FEATURE

\title{
Training, Support, and Connection for Student Library Employees in a Tiered Reference Service Model
}

Student employees at circulation desks are the first points of contact for many library users with research questions, but they are challenged to respond or refer when librarians are unavailable. In an attempt to cultivate student employees' reference skills, confidence, and connection to the library's values and mission, the Engineering and Physical Sciences Division of the UC Berkeley Library developed an outcomes-based training program consisting of an interactive session and a dynamic online reference manual. Student employees completed pre-training and post-training assessments of their reference skills and self-efficacy. Qualitative feedback was analyzed to identify ongoing challenges and intangible benefits for student employees engaged in reference work. Challenges observed include user expectations, infrequent questions, and the complex information landscape; benefits observed include community building and student growth. Implications of these challenges and benefits for student training programs are discussed.

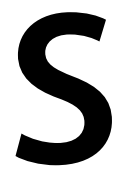

ince it initially gained attention as the Brandeis Research Consultation Model, ${ }^{1}$ the tiered or triage reference model has been implemented in many academic libraries. ${ }^{2}$ In this model, student employees and staff answer directional and basic reference questions at the circulation desk while making referrals of more complex questions to subject librarians as appropriate. While library users have long turned to the circulation desk as the first place to ask their research questions, this tiered approach has necessarily increased as reference desks have been closed or consolidated and librarians have begun spending more time outside the library collaborating with faculty and campus partners. As the front line staff at circulation desks, student employees are called upon to triage questions at the desk but are challenged to respond or refer when librarians are not available. This is especially true at smaller subject libraries where staffing is limited.

To help improve the reference skills, confidence, and sense of values and community among its student employees, the Engineering and Physical Sciences (EPS) Division of the UC Berkeley Library implemented a student library employee (SLE) reference training program consisting of an interactive training session and a dynamic online reference manual continuously improved through student feedback. The training also explicitly reinforced the value of the student employees' contributions to the mission of the library. This study initially
Brian D. Quigley, Jeffery L. Loo, Lisa Ngo, Susan Powell, Samantha Teplitzky, Anna Sackmann, Kortney K. Rupp

Brian D. Quigley, Head, Engineering and Physical Sciences Division, University of California, Berkeley Library; email:bquigley@berkeley.edu. Jeffery L. Loo, Clinical Librarian, University of California San Diego Library;email:jloo@ucsd.edu. Lisa Ngo, Engineering Librarian, University of California, Berkeley Library; email:Ingo@berkeley.edu. Susan Powell, GIS and Map Librarian, University of California, Berkeley Library;email:smpowell@berkeley.edu. Samantha Teplitzky, Open Science Librarian, University of California, Berkeley Library; email:steplitz@ berkeley.edu. Anna Sackmann, Data Services Librarian, University of California, Berkeley Library; email: asackmann@berkeley.edu. Kortney K. Rupp, Chemical Information Librarian, University of California, Berkeley Library; email:kortneyrupp@gmail.com.

Reference \& User Services Quarterly, vol. 59, no. 3/4, pp. 195-203 (c) 2021 American Library Association. All rights reserved.

Permission granted to reproduce for nonprofit, educational use. 


\section{FEATURE}

intended to quantitatively evaluate the impact of this outcomes-based training design and to share the effective materials from it, but a small sample limited the statistical analysis. Instead we refocused on a qualitative analysis of the study's open-ended questions to identify challenges that persist for student employees and their implications for student employee training programs.

\section{BACKGROUND AND CONTEXT}

Like many other libraries, the UC Berkeley Library has been evolving its reference services and transforming the role of the subject liaison. Aligned with the Association of Research Libraries (ARL) engagement with the changing role of liaisons, ${ }^{3}$ this includes expanding roles in outreach, information literacy, scholarly communications, research data management, open science, and faculty partnerships. These new and expanded roles encourage librarians to spend time out of the library and in academic departments.

The UC Berkeley Library consists of twenty-three libraries including sixteen subject libraries that are clustered into four divisions: Arts and Humanities, Engineering and Physical Sciences, Life and Health Sciences, and Social Sciences. The EPS Division includes five libraries: Chemistry and Chemical Engineering Library, Earth Sciences and Map Library, Kresge Engineering Library, Mathematics Statistics Library, and Physics-Astronomy Library.

While some campus libraries continue to staff reference desks with regular reference hours, the context within the EPS Division requires a tiered reference model. When we began planning our SLE reference training program in 2013, three librarians covered the five libraries within the division. It was essential for student employees to be able to answer and refer questions asked at the circulation desks. While the staffing situation has since improved, our expanded liaison roles limit the availability of librarians to respond to reference questions whenever they are asked in our libraries. In fact, student employees continue to answer the majority of questions asked at our desks: in the most recent year, they answered nearly six thousand directional questions and more than one thousand reference questions. This accounted for 85 percent of all the questions answered in the EPS Division and nearly half of all our reference questions. The question therefore remains the same: how do we provide consistent reference services in-person when librarians are not always available?

We developed the SLE reference training program with the goal of improving reference services by enhancing the quality and consistency of student employee answers and increasing referrals to librarians. This effort built upon the training already provided by circulation supervisors. As a first step, we conducted a reference audit at our five libraries to understand the types and frequency of questions asked at our circulation desks to inform the design of the training program. Through this audit, we confirmed that the majority of reference questions were answered by student employees. ${ }^{4}$ Furthermore, we determined that most of those questions could be sufficiently answered by student employees with proper training. This reinforced our decision to develop the training program and led to a focus on training for answering common reference questions-defined as questions that do not require subject knowledge and generally take under three minutes-and referring more intensive ones to librarians.

\section{LITERATURE REVIEW}

Research in librarianship has addressed the value of reference work in the academic library setting, the roles and training of student employees, and the value, growth, and evaluation of student employees, laying a foundation for our study.

\section{Value of Reference}

Todorinova and Torrence describe how academic reference librarians serve as the link between the library, its resources, and users. ${ }^{5}$ As budgets for staffing have decreased over time, reference librarians are often unable to serve as the first contact for user queries. To respond to this limitation, many libraries have shifted their reference services to the one-desk model, making ongoing and active training necessary for an effective user experience. Bunnett et al. employed a methodical approach to reduce and ultimately eliminate the dedicated presence of librarians at service desks at Indiana State University after seeing a 45 percent reduction in reference interactions over five years. ${ }^{6}$ They found that the consolidation of desks led to increased instructional opportunities for librarians at the institution. LaMagna, Hartman-Caverly, and Marchetti also outline the implementation process for a tiered or triage reference model. ${ }^{7}$ The literature on this topic indicates that such models enable academic librarians to focus their efforts on providing in-depth reference consultations by appointment and information literacy instruction.

\section{Training Student Employees}

Student employees provide a vital service to libraries by taking on a range of daily tasks and offering consistent service to patrons. Thomsett-Scott calls attention to how the quality of service received from student employees compared to librarians in a one-desk model. ${ }^{8}$ However, student employees already make up approximately 22 percent of library staff in doctoral institutions, ${ }^{9}$ and many studies report positive findings. Keyes and Dworak found that student employees were able to provide comparable customer service when staffing an online chat reference platform. ${ }^{10}$ Vilelle and Peters also found success in training library shelvers to respond to basic reference questions and refer when necessary. ${ }^{11}$ Connell and Mileham emphasize that training student employees in basic reference skills is a key factor to the success of 
such service models. ${ }^{12}$ Wong argues that users will direct their questions to the most convenient or welcoming service points rather than identify individuals appropriately trained to assist them. ${ }^{13}$ Understanding this information-seeking behavior supports the investment of time in training student employees. ${ }^{14}$

Other works address various models for training student library employees, including specific topics to be covered in training, ${ }^{15}$ specific skills needed in science libraries, ${ }^{16}$ and overhauling training programs through student input. ${ }^{17}$ However, it is not enough to simply train students on policies and procedures. In discussing the role that undergraduates now play in many institutions as peer-to-peer reference providers, Fargo comments, "To create these meaningful employment opportunities, we must commit time to set up the training, provide the necessary scaffolding to give our students the skills they need to participate in a reference conversation." ${ }^{\text {18 }}$

\section{Value to Student Employees}

In addition to organizational contributions, student library employment may also promote personal growth and academic success for the student as evidenced in a systematic review by Mitola, Rinto, and Pattni. ${ }^{19}$ While much of the literature on student training programs focuses on the positive effects of well-trained students on library operations, recent research takes into account how student library employment can support and encourage student development in their own endeavors. Hoag and Sagmoen note that on-campus student employment has been shown to increase student motivation, performance, and overall engagement with the educational experience. ${ }^{20}$ Using the Social Change Model of leadership development, Milton and Meade found that students who learn to promote library resources through experiential learning also grow and develop as leaders. ${ }^{21}$ Open communication, engagement within the library community, and constant redevelopment of student employee programs foster opportunities for leadership. However, Charles, Lotts, and Todorinova's survey of 350 student library employees found that while students report a generally positive experience working in the library, they may have a limited understanding of the rewards of their positions, and at the same time the library may not be tapping into the full potential of their contributions. ${ }^{22}$ Communicating the value of library employment to students beyond their immediate roles has strong implications for training.

\section{Qualitative Evaluations of Training}

Part of understanding whether a training program is effective depends on the accurate assessment of student understanding both in the training session itself, but also more broadly in employee performance on a daily basis. Previous studies have highlighted the role for qualitative assessment of student work experiences in the library. Brenza,
Kowalsky, and Brush discuss student workers' perceptions of the library as a result of their employment experiences. ${ }^{23}$ Student employee responses demonstrated a disconnect between students' training to answer specific common reference questions and expectations that students will gain a more abstract and nuanced understanding of the role of the library and its services. Student roles are not always clearly defined so librarian perceptions of students' responsibilities may differ from the day-to-day experiences. In Stevens and Mundt's work, students wrote reflective statements about their work experience in a research commons. Assessment of these reflections ascertained the value of this practice as part of student job duties. Tellingly, the authors note, "written reflection doesn't always have to have an immediate, quantifiable benefit to be valuable to the Research Commons and to our team."24 Becker-Redd, Lee, and Skelton instituted post-training surveys later in the semester to give students an opportunity to reflect on the effectiveness of their training session and identify areas where more guidance is needed..$^{25}$ These studies lay the groundwork for our qualitative evaluation of student employee experience.

Our study contributes to the body of literature on student employee training in an academic library with a tiered reference desk model. It weaves together threads from prior research on the importance of reference work, the changing roles of liaison librarians, and the need for, training of, and assessment of student employees. This work provides an outcomes-based approach to training student employees for reference work that employs qualitative feedback to identify ongoing challenges and upholds the value of student library employees to the larger mission of the library.

\section{SLE REFERENCE TRAINING PROGRAM}

All EPS Division student employees are invited to attend our annual SLE Reference Training in the fall semester. The two-hour session provides an interactive experience that encourages discussion and collaboration. For learning objectives, students should be able to accomplish the following after training:

1. Recognize other SLEs and build a sense of team spirit

2. Articulate the role of SLE reference services in the mission of our academic library

3. Follow the tiered reference workflow

4. Understand the information landscape in engineering and the physical sciences

5. Recognize and find subject-specific resources

6. Use the SLE Reference Manual for procedures in managing reference questions

7. Respond to common reference questions

8. Refer intensive reference questions to the appropriate subject librarian

9. Follow guidelines for good library service 


\section{FEATURE}

Using some of the training practices identified by Stanfield and Palmer, ${ }^{26}$ the session reinforces these learning objectives through lecture content, discussion, and activities. For instance, to build a sense of team spirit (Objective 1), the students play a game of human bingo as an icebreaker. While all the objectives above are covered in the training, we focus primarily on the four objectives described here.

Objective 3: Follow the tiered reference workflow. Student employees learn about the meaning of "reference" in the context of libraries and identify the three types of questions asked at service desks: directional, common reference, and intensive reference. As a group, the students recall questions they have received at the desk and then categorize each question. They also review which library staff are responsible for answering each type of question. Specifically, intensive reference questions should be referred to subject librarians while directional and common reference questions can be answered by students and circulation staff.

Objective 6: Use the SLE Reference Manual. Students review an online manual on addressing common questions when a supervisor or librarian is not available. The manual includes the most commonly asked questions at our libraries-as identified through our month-long reference audit-and provides step-by-step procedures and scripts for answering them. Most importantly, the manual is a flexible document; it is open for commenting by student employees and staff so that we can edit or add content in a timely manner.

Objective 7: Respond to common reference questions. Over a quarter of the training session is spent on helping students learn to respond accurately and confidently to common reference questions. Small groups of 3-4 students work on case study exercises that address finding journal articles, finding books, finding specialized software, general library use questions, and library-specific questions (e.g., finding air photos at the Earth Sciences and Map Library).

Objective 8: Refer intensive reference questions to the appropriate subject librarian. The training emphasizes the need to recognize intensive reference questions and to refer them to the appropriate subject librarian. Students are given a suite of tools for referrals including a web-based Ask a Science Librarian form and contact information for our subject experts.

\section{METHODOLOGY}

Prior to 2017, evaluation of the training program consisted of a brief post-training survey to assess how useful students found different elements of the training. As part of the development of our study in 2017, we redesigned our assessment tool to address the study's research questions, adding a pretraining component as well as self-assessment and referenceassessment questions. As a result, in fall 2017, both qualitative and quantitative data were collected via pre-training and post-training assessment surveys conducted using Qualtrics online survey software. The training session took place in late October. Distributed approximately one month prior to this session, the pre-training assessment contained three sections. Self-assessment questions determined student confidence answering and referring questions on a five-point Likert scale. Reference assessment questions contained a series of common questions encountered at our circulation desks with multiple choice answers; this section was "open book" wherein students could use any available resources to answer the questions. Open-ended questions collected students' views on reference challenges and training at the circulation desk.

The post-training assessment, distributed approximately one month after the training session, contained four sections. Three sections were similar to those in the pre-training assessment to allow comparisons; an additional section on training satisfaction evaluated student reactions to the training itself. Average gain scores were calculated for attendees and non-attendees to compare their improvement on the reference assessment questions. Emergent thematic coding was used to identify themes within the qualitative responses.

Surveys were distributed to all student employees regardless of whether or not they attended the training in order to compare the two groups. In compliance with the policies of the UC Berkeley Institutional Review Board, participation in the pre-training and post-training assessments was voluntary and anonymous. To match pre-training and post-training scores anonymously, we relied on students to correctly enter matching and untraceable identification numbers (using a portion of their student ID numbers) when completing the assessments. In an effort to increase participation, we held a gift card prize drawing that all student employees could enter.

The reference manual, lesson plan, case study exercises, pre-training survey, and post-training survey are available as supporting materials. ${ }^{27}$

\section{RESULTS}

During fall 2017, the EPS Division libraries employed thirtyeight student employees. Of these students, twenty-three attended our reference training in October 2017. All student employees were invited to complete the surveys, but to be included in the quantitative analysis, they needed to attend the training and complete both the pre-training survey and post-training survey. Twenty-seven participants began the pre-training assessment; however, only twenty-one surveys were completed (figure 1). The post-training assessment was started by twenty participants and completed by fourteen participants, but rendered only twelve survey responses that could be matched to a pre-training survey response. Of those twelve responses, nine participants indicated they had attended the training session. This implies a 23.7 percent completion rate of the full study among all student employees (i.e., nine participants among a student employee population of thirty-eight).

The study was structured around a pre-training and posttraining survey, but with only nine responses available for 
quantitative comparison, the small sample size did not lead to broader conclusions. In the interest of transparency, quantitative results are appended (see appendix 1). Despite the small sample size, we hope the inclusion of these findings will be valuable to library researcherswho may be considering similar study methods, particularly involving student employees. Due to these limited quantitative results, we pivoted our focus to an analysis of the study's openended questions. To be eligible for the qualitative analysis, participants simply needed to complete at least one open-ended question on either survey. Across the two surveys, nineteen unique participants (50 percent of our student library employees) responded to one or more of the openended questions. We used this analysis to identify the challenges student employees face, those that persist after training, and the implications for improving student training.

\section{Challenges SLEs Encounter}

In the pre-training assessment, participants were asked: "In general, what are the biggest challenges you face in helping users with reference questions?" Through emergent thematic coding, participants' free-text responses fit into five themes: insufficient subject and reference expertise, working with user expectations, navigating and understanding resources, finding library materials, and lack of practice with obscure questions. Within the first theme of insufficient subject and reference expertise, participants commented on the challenge of directing users to the most helpful source, answering open-ended questions, and understanding when to refer to a librarian. One participant's comment encapsulates the multiple challenges of the reference experience.

The biggest challenges that I face in helping patrons with reference questions is trying to understand the question that they are asking. They may come to the desk with topics that I am unfamiliar with so I struggle at first to understand what they are asking to then determine whether it is something I can help them myself with or if I should refer them to a librarian.

For some participants, concerns about insufficient expertise persisted following the training, especially related to managing open-ended questions. In the post-training assessment, they commented on the difficulty of understanding unfamiliar keywords and what users are asking.

Five participants commented on the challenge of working with user expectations. One noted how users may become impatient, and others described feeling time pressure, which leads them to "get nervous" and "blank out" while attempting to answer questions. Another participant commented that some users appear to disregard student employees and prefer assistance from a librarian or staff supervisor.

Navigating library resources and finding materials also emerged as particular challenges, especially in regard to finding journals, locating maps, and understanding the various navigation paths to resources. These themes persisted in the post-training assessment comments, with students again noting the difficulty in knowing the most efficient way to find a specific journal or article. One student commented:

I feel like there are so many different websites, search options, and different databases available that it can be difficult to figure out which one would be the best way to search for what the patrons need.

Finally, participants expressed concern about their lack of practice with infrequent questions. Participants said they are not accustomed to answering less frequent or intensive questions such as finding a thesis or using a specific database. One participant commented on the need for additional practice:

[The] biggest challenge I face is not having enough practice and not being familiar with how to answer the questions so it takes me a little longer to come to a conclusion.

\section{Opportunities for Improvement}

In the post-training survey, participants were asked how their skills in helping users with reference questions could be improved. Their responses fell into four themes: utility of training sessions, need for additional practice, standardized and simplified navigation, and familiarity with the library website. 


\section{FEATURE}

In terms of training utility and the need for practice, participants expressed appreciation for the training sessions and demand for further training. Three participants commented on the need for more practice opportunities, specifically involving the retrieval of newspaper articles and maps. Two participants affirmed that the training sessions would improve their reference skills.

Additionally, participants commented on the need for standardized and simplified navigation. This relates back to the challenge noted in the pre-training assessment of navigating through our multitude of online resources. One participant suggested a "flexible step process" that begins with a concise overview of the multiple methods for starting a search. Another student commented on quick access to guides:

Make access to the LibGuides or reference guide very easy and fast, maybe from a centralized page of URLs.

Finally, participants wished to gain greater familiarity with the library website. Their comments highlighted the need for regular reviews of the site to remain familiar with the range of useful guides, information, and tools available there.

Should [new student employees] have any patrons that need to know more about guides or software, that site has a lot of information. Supplementing that with the manual is very helpful.

Overall participants rated the training highly and learned lessons from it. Yet their comments indicate that challenges persist and improvements could be made. What do these results mean for training student employees and providing reference service?

\section{DISCUSSION}

Over time we have learned that training attendees find the session helpful; student employee comments identify the case study exercises as a particularly useful component and indicate they wish to spend more time on them for learning. At the same time, our analysis of their qualitative feedback indicates there is room for improvement as we address the following challenges: user expectations, infrequent questions, and the complex information landscape. Our analysis also identified benefits of our training program such as community building and student growth that could be cultivated and strengthened in the future.

\section{Strike a Balance: Managing Expectations and Referring}

A critical theme highlighted by our study is the tension between user expectations of immediate service and a tiered reference model where complex questions are referred and answered later. Our student employees are caught between dueling expectations to provide reference services and to refer to librarians. Students clearly care about providing good public service, as indicated by their thoughtful responses to questions about service challenges. For example, after the training some participants commented that they still felt pressure to answer complex reference questions, which implies the training was perhaps less successful at validating the tiered reference model workflow and increasing referrals to librarians. Additionally, several participants commented on lingering confusion around recognizing questions that need to be referred. In short, even post-training, it appears that student employees still feel a need to answer complex reference questions, in part due to user impatience and in part due to confusion about the expectations and outcomes of the tiered reference model.

Training implications. To improve student understanding, we could better clarify the purpose of the training, both for planning the session and introducing its objectives to participants. Is the training's purpose to help student employees become better at managing reference questions, to encourage them to refer, or both? Being an effective student employee in the tiered reference model requires a balance of confidence in order to answer simple reference questions accurately and of self-awareness of one's limitations in order to refer appropriately. To further clarify the role of student employees within the tiered reference workflow, we could also collaborate with the circulation supervisors to develop clear guidelines and outcomes related to our expectations of student employees.

Additionally, student employees may feel confusion or hesitation about referrals because they do not understand the full landscape of reference work. To address this problem, the training on referrals should be shifted to emphasize the reference interaction after the referral as opposed to focusing solely on the student's role. For example, the training could walk students through an example of an intensive reference question and explain how the user and librarian both benefit from the interaction, and consequently, student employees may feel less pressure to answer reference questions themselves and be more comfortable referring to a librarian.

\section{Few and Far Between: Practicing Infrequent Questions}

Participants cited the lack of practice with infrequent questions as an obstacle to success. Our training focuses on teaching student employees to identify common reference questions and appropriately manage them. Yet during the study period, student employees reported not gaining sufficient experience with infrequent and intensive questions to feel comfortable differentiating, answering, and referring them.

Training implications. Two solutions could address this lack of practice opportunities for infrequent questions. First, we could institute regular reference audits in the EPS 
Division to confirm the common versus infrequent reference questions being asked at the circulation desk. Since the 2013 audit, the overall number of reference questions has been declining, and it is unclear if the same categories of questions are being asked. As a result, student employees may have less opportunity to practice answering the reference questions that we address in our case studies and reference manual. Regular reference audits would assess the types of questions being asked and verify that content covered in our training continues to match the experiences of student employees.

As a second approach, we could offer students more consistent practice with reference questions throughout the year. We began to implement this approach in spring 2018. Student employees now take two refresher quizzes per semester which allow them to work through case studies similar to those at the annual training. Each quiz consists of three questions, a mix of circulation and reference questions for a total of twelve questions throughout the year (six circulation and six reference). Student employees' reference question responses are reviewed by librarians, and then circulation supervisors personally provide feedback to each student employee to coach them. These refresher quizzes grant additional opportunities for student employees to practice managing infrequent questions.

\section{Too Many Paths: Navigating Multiple Resources}

Many participants commented on the confusing array of resources available for searching and answering users' reference questions. While our online reference manual strives to outline simple and explicit procedures for conducting searches and responding to users, the complexity of the information landscape leaves student employees uncertain about the most efficient approaches. As an example, there is confusion about whether to search and demonstrate the library's discovery layer or the classic local catalog.

Training implications. To counter this confusion, we could simplify procedures further and direct student employees to a smaller set of resources. While this might alleviate confusion, it would also mask the complexity of our library environment and might not serve the student employees' growth as learners and researchers. As an alternate approach, we could incorporate an information literacy component into the training session. Focusing on the frames of "Information Creation as a Process" and "Searching as Strategic Exploration" from the ACRL Framework for Information Literacy for Higher Education, ${ }^{28}$ we could teach student employees to understand the information landscape, choose appropriate databases and search strategies, and evaluate resources. By emphasizing these underlying information literacy concepts in addition to basic reference procedures, we could help students improve as library employees while also benefiting their academic learning and research.

\section{Intangible Positives: Community Building and Student Growth}

While there are still challenges to be addressed, we have also identified benefits of the training program to the EPS Division and our student employees. For one, the training program provided the opportunity for cross-training student employees so they can be prepared to answer reference questions at all five libraries in the division. Consequently, students may serve as substitutes at different libraries and manage a range of library-specific questions. Bringing our full cohort of student employees together has also reinforced the mission of the libraries, fostered community among the students, and connected the students with librarians.

In addition, the training program partly addressed the affective domain of student learning and engaged the highimpact practices of student library employment identified by Mitola, Rinto, and Pattni. ${ }^{29}$ For example, the training program engaged the students in the substantive work of answering reference questions and promoted peer mentoring during the case study exercises.

Training implications. When we initiated this training program, we set out with objectives for improving student employee performance in answering common reference questions and referring intensive questions. Through the process of conducting this study, our perspective has shifted to a more holistic view, encompassing the intangible positives that student employees might gain from their work at the library. This will require increased focus on affective factors, such as building confidence and providing experiences that will promote student success and retention. As reflected in their comments, our reference training did not adequately address student employees' concerns about their lack of subject expertise. Perhaps by taking into account how their library employment fits into their greater academic and personal experience, we can better support student employees and relieve some of the anxiety around their perceived need to always have the answer.

\section{CONCLUSION AND FUTURE WORK}

This article shares our strategies for an outcomes-based student library employee reference training program connected to library values and mission. Through the analysis of comments from student library employees engaged in reference work at circulation desks, the study identifies challenges that persist after training, which include reluctance to refer questions, difficulty in recalling procedures, and confusion about the large number of resources and strategies available. Improvements such as regular refresher quizzes and more focus on affective factors could address these challenges.

Future work could assess the effectiveness of our suggested training improvements, particularly how the pairing of refresher quizzes with the annual training influences students' ability to answer reference questions and refer to 


\section{FEATURE}

librarians. Another direction is investigating the broader impact of the training's intangible positives. There are opportunities to explore how the training's community building efforts influence students' dedication to their library work, whether increased confidence in reference work impacts their broader academic experiences, and which practices help student employees manage user expectations.

\section{References}

1. Virginia Massey-Burzio, "Reference Encounter of a Different Kind: A Symposium," Journal of Academic Librarianship 18, no. 5 (1992): 276-80.

2. Jason Coleman, Melissa N. Mallon, and Leo Lo, "Recent Changes to Reference Services in Academic Libraries and Their Relationship to Perceived Quality: Results of a National Survey," Journal of Library Administration 56, no. 6 (2016): 673-96, https://doi.org /10.1080/01930826.2015.1109879.

3. Association of Research Libraries, "Reimagining the Library Liaison," accessed June 12, 2019, https://www.arl.org/resources /reimagining-the-library-liaison/.

4. Jeffery Loo et al., "Empowering the Frontline: A Dynamic Online Reference Manual and Training Session for Student Library Employee Reference Skills" (poster presented at the American Library Association Annual Conference, San Francisco, CA, June 2015), https://escholarship.org/uc/item/24m5v7ps.

5. Lily Todorinova and Matt Torrence, "Implementing and Assessing Library Reference Training Programs," Reference Librarian 55, no. 1 (2014): 37-48, https://doi.org/10.1080/02763877.201 4.853277 .

6. Brian Bunnett et al., "Where Did the Reference Desk Go? Transforming Staff and Space to Meet User Needs," Journal of Access Services 13, no. 2 (2016): 66-79, https://doi.org/10.1080/15367 967.2016.1161517.

7. Michael LaMagna, Sarah Hartman-Caverly, and Lori Marchetti, "Redefining Roles and Responsibilities: Implementing a Triage Reference Model at a Single Service Point," Journal of Access Services 13, no. 2 (2016): 53-65, https://doi.org/10.1080/15367 967.2016.1161516.

8. Beth Thomsett-Scott, "Creating a Formal Program to Train LIS Students for Reference Services," Reference Librarian 53, no. 1 (2012): 41-59, https://doi.org/10.1080/02763877.2011.591666.

9. Association of College and Research Libraries, Academic Library Trends \& Statistics 2016 (Chicago: Association of College and Research Libraries, 2017), 638.

10. Kelsey Keyes and Ellie Dworak, "Staffing Chat Reference with Undergraduate Student Assistants at an Academic Library: A Standards-Based Assessment," Journal of Academic Librarianship 43, no. 6 (2017): 469-78, https://doi.org/10.1016/J .ACALIB.2017.09.001.

11. Luke Vilelle and Christopher C. Peters, "Don't Shelve the Questions: Defining Good Customer Service for Shelvers," Reference $\&$ User Services Quarterly 48, no. 1 (2008): 60-67, https://doi .org/10.5860/rusq.48n1.60.

12. Ruth Sara Connell and Patricia J. Mileham, "Student Assistant Training in a Small Academic Library," Public Services Quarterly 2, no. 2-3 (2006): 69-84, https://doi.org/10.1300 /J295v02n02_06.

13. Gabrielle K.W. Wong, "Information Commons Help Desk Transactions Study," Journal of Academic Librarianship 36, no. 3 (2010): 235-41, https://doi.org/10.1016/J.ACALIB.2010.03.006
14. Jane M Kathman and Michael D Kathman, "Training Student Employees for Quality Service," Journal of Academic Librarianship 26, no. 3 (2000): 176-82, https://doi.org/10.1016/S0099 $-1333(00) 00096-3$.

15. Andrea G. Stanfield and Russell L. Palmer, "Peer-ing into the Information Commons," Reference Services Review 38, no. 4 (2010): 634-46, https://doi.org/10.1108/00907321011090773.

16. Melissa K. Aho, Anne M. Beschnett, and Emily Y. Reimer, "Using an Untapped Resource: Expanding the Role of the Student Worker at the Bio-Medical Library," Public Services Quarterly 6, no. 1 (2010), 65-68, https://doi.org/10.1080/15228950903523579.

17. Kindra Becker-Redd, Kirsten Lee, and Caroline Skelton, "Training Student Workers for Cross-Departmental Success in an Academic Library: A New Model," Journal of Library Administration 58, no. 2 (2018), 153-65, https://doi.org/10.1080/01930826.20 17.1412711.

18. Hailley Fargo, "They CAN and They SHOULD and It's BOTH AND: The Role of Undergraduate Peer Mentors in the Reference Conversation," In the Library with the Lead Pipe, December 26, 2018, http://www.inthelibrarywiththeleadpipe.org/2018/they -can-and-they-should-and-its-both-and/.

19. Rosan Mitola, Erin Rinto, and Emily Pattni, "Student Employment as a High-Impact Practice in Academic Libraries: A Systematic Review," Journal of Academic Librarianship 44, no. 3 (2018): 352-73, https://doi.org/10.1016/j.acalib.2018.03.005.

20. Beth Hoag and Sarah Sagmoen, "Leading, Learning, and Earning: Creating a Meaningful Student Employment Program," in Students Lead the Library: The Importance of Student Contributions to the Academic Library, ed. Sara Arnold-Garza and Carissa Tomlinson (Chicago: Association of College and Research Libraries, 2017), 1-20.

21. Suzanne Milton and Qing H. Meade, "More Than Just a Student Voice: Facilitating Student Leadership Development Through the Library Student Liaison Program," Journal of Library Administration 58, no. 4 (2018): 346-363, https://doi.org/10.1080/019 30826.2018.1448650

22. Leslin H. Charles, Megan Lotts, and Lily Todorinova, "A Survey of the Value of Library Employment to the Undergraduate Experience," Journal of Library Administration 57, no. 1 (2017): 1-16, https://doi.org/10.1080/01930826.2016.1251248.

23. Andrew Brenza, Michelle Kowalsky, and Denise Brush, "Perceptions of Students Working as Library Reference Assistants at a University Library," Reference Services Review 43, no. 4 (2015): 722-36, https://doi.org/10.1108/RSR-05-2015-0026.

24. Elliott Stevens and Madeline Mundt, "I Remember...': A Written-Reflection Program for Student Library Workers," In the Library with the Lead Pipe, November 14, 2018, http://www .inthelibrarywiththeleadpipe.org/2018/i-remember-a-written -reflection-program-for-student-library-workers/.

25. Becker-Redd, Lee, and Skelton, "Training Student Workers for Cross-Departmental Success."

26. Stanfield and Palmer, "Peering into the Information Commons."

27. Brian Quigley et al., "Training and Support for Student Library Employees in a Tiered Reference Service Model: Supporting Materials," UC Berkeley Dash, 2018, https://doi.org/10.6078 /D1PD6W

28. Association of College and Research Libraries, "Framework for Information Literacy for Higher Education," accessed June 12, 2019, http://www.ala.org/acrl/standards/ilframework.

29. Mitola, Rinto, and Pattni, "Student Employment as a HighImpact Practice." 


\section{APPENDIX 1: QUANTITATIVE RESULTS}

\section{Training Session Evaluation}

Participants responded to statements regarding self-efficacy and answered questions that evaluated the usefulness of the training session on a five-point Likert scale. Overall they rated the training session as more than satisfactory and helpful, with students who attended previous training sessions rating more highly (table 1 ).

Participants also completed multiple-choice sample reference questions to assess their ability to accurately respond to questions. The nine participants who had attended the training showed greater improvement with an average gain score of $12.3 \%$ (table 2). A one-sample t-test determined whether the mean gain score among SLEs who attended the training is significantly different from zero. The mean gain score
$(\mathrm{M}=12.22, \mathrm{SD}=11.60)$ was a statistically significant difference, $95 \% \mathrm{CI}$ [3.31 to 21.13], $\mathrm{t}(8)=3.162, \mathrm{p}=0.013$.

Three of the participants did not attend the training session; however, having gained additional experience since the pre-training survey, they still showed improvement with an average gain score of $7.4 \%$ between their pre-training to post-training assessments.

In the self-assessment sections of the surveys, participants rated their ability to answer reference questions before and after the training session. On average, participants improved in their confidence to answer reference questions. Those with previous training had a higher sense of self-efficacy, but those with no previous training reported a decrease in their confidence to refer questions appropriately.

Table 1. Training Session Evaluation

\begin{tabular}{lccc}
\hline & $\begin{array}{c}\text { No Previous Training } \\
(\mathbf{n = 6 )}\end{array}$ & $\begin{array}{c}\text { With Previous Training } \\
(\mathbf{n = 3}=\mathbf{3})\end{array}$ & $\begin{array}{c}\text { Respondents Overall } \\
(\mathbf{n}=\mathbf{9})\end{array}$ \\
How satisfied were you with the training? & $4.50(0.55)$ & $5.00(0.00)$ & $4.67(0.50)$ \\
How helpful was the training session on your & $4.00(0.63)$ & $5.00(0.00)$ & $4.33(0.71)$ \\
ability to help with user reference questions? & & &
\end{tabular}

Average rating (standard deviation):

1 = not satisfied/not helpful; 5=very satisfied/very helpful

Table 2. Average Pre- and Post-Training Assessment Scores

\begin{tabular}{|c|c|c|}
\hline & $\begin{array}{l}\text { Participants Attended Training } \\
\qquad(\mathrm{n}=9)\end{array}$ & $\begin{array}{l}\text { Participants } \\
\text { Did Not Attend Training } \\
(\mathbf{n}=3)\end{array}$ \\
\hline Pre-Training & $\begin{array}{c}80.2 \% \\
\text { (s.d. }=15.5 \%)\end{array}$ & $\begin{array}{c}\quad 77.8 \% \\
\text { (s.d. }=11.1 \%)\end{array}$ \\
\hline Post-Training & $\begin{array}{c}92.6 \% \\
\text { (s.d. }=9.6 \%)\end{array}$ & $\begin{array}{c}85.2 \% \\
\text { (s.d. }=17.0 \%)\end{array}$ \\
\hline Gain Score & $\begin{array}{c}12.3 \% \\
\text { (s.d. }=11.7 \%)\end{array}$ & $\begin{array}{c}7.4 \% \\
\text { (s.d. }=23.1 \%)\end{array}$ \\
\hline
\end{tabular}

Table 3. Self-efficacy Ratings

\begin{tabular}{|c|c|c|c|c|c|c|}
\hline & \multicolumn{2}{|c|}{$\begin{array}{l}\text { No Previous } \\
\text { Training } \\
(n=6)\end{array}$} & \multicolumn{2}{|c|}{$\begin{array}{l}\text { With Previous Training } \\
\qquad(n=3)\end{array}$} & \multicolumn{2}{|c|}{$\begin{array}{l}\text { Respondents } \\
\text { Overall } \\
(n=9)\end{array}$} \\
\hline & Pre & Post & Pre & Post & Pre & Post \\
\hline $\begin{array}{l}\text { Overall, I am confident that I can help } \\
\text { users with their reference questions. }\end{array}$ & $3.67(0.52)$ & $4.00(0.89)$ & $5.00(0.00)$ & $5.00(0.00)$ & $4.11(0.78)$ & $4.33(0.87)$ \\
\hline $\begin{array}{l}\text { If I can't answer a reference question, I } \\
\text { am confident that I can refer the user to } \\
\text { the appropriate person for help. }\end{array}$ & $4.67(0.52)$ & $4.50(0.84)$ & $5.00(0.00)$ & $5.00(0.00)$ & $4.78(0.44)$ & $4.76(0.71)$ \\
\hline $\begin{array}{l}\text { I have received sufficient library training } \\
\text { to handle reference questions. }\end{array}$ & $4.00(0.63)$ & $4.17(1.17)$ & $5.00(0.00)$ & $5.00(0.00)$ & $4.33(0.71)$ & $4.44(1.01)$ \\
\hline
\end{tabular}

Average rating (standard deviation): 1 = strongly disagree; 5 = strongly agree 